\title{
Shear Wave Elastography as an Early Indicator of Breast Cancer in a Breastfeeding Patient: A Case Report and Literature Review
}

\author{
Ayşegül Altunkeser and Fatma Zeynep Arslan* \\ Department of Radiology, Konya Training and Research Hospital, University of Health Science, Turkey

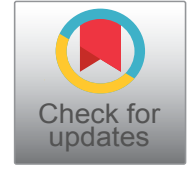

*Corresponding author: Fatma Zeynep Arslan, MD, Konya Training and Research Hospital, University of Health Science, Hacı Şaban Mah, Meram Yeni Yol Caddesi, No: 97, PC: 42090, Meram, Konya, Turkey, Tel: 0506-438-24-30, Fax: 0-332323-67-23

\begin{abstract}
Shear wave elastography (SWE) is a relatively new and highly effective method to reveal mechanical features of tissue by demonstrating quantitative elasticity value. The morphological features including margin of the lesion, orientation, shape and border are considered in differentiation of breast lesions on USG. It is a known fact that malignant lesions are usually palpated as a hard mass in the physical examination. A qualitative broad information can obtain about the tissue elasticity by integrating SWE examination into the classical USG evaluation. We reported the finding of SWE examination in breastfeeding patient with breast malignancy in addition to magnetic resonance imaging (MRI) and ultrasonography (USG) findings.
\end{abstract}

\section{Keywords}

Shear wave elastography, Invasive ductal carcinoma, Breastfeeding

\section{Introduction}

Shear wave elastography (SWE) is a relatively new and highly effective method to reveal mechanical features of tissue by demonstrating quantitative elasticity value [1]. Qualitative and quantitative elasticity values can be helpful in differentiating malignant breast lesions from benign ones [2]. Herein, we reported the finding of SWE examination in breastfeeding patient with breast malignancy in addition to magnetic resonance imaging (MRI) and ultrasonography (USG) findings.

\section{Case Report}

A 27-year-old young female patient admited to our hospital complaining from pain in the right breast. In the young patient with no history of cancer in the family; The patient was breasfeeding and labaratuary findings were normal. On physical examination, a hard mass was palpated in her right breast. A hypoechoic mass lesions was sonographically detected on the right breast in a diameter with $31 \times 24 \mathrm{~mm}$ (Figure 1). SWE was performed to obtain additional information about mass lesion. Many stiff areas observed within mass lesion on color elasticity mapping. Mean elasticity value was $6.04 \mathrm{~m} / \mathrm{s} 101.4 \mathrm{kPa}$ on consecutive measurement (Figure 2). A core needle biopsy was performed immediately. One of the most important reason of the immediate core needle biopsy was the detection of quite hard mass on SWE. Thus, SWE examination prevented a possible delay in diagnosis in this young, breastfeeding patient. Invasive ductal carcinoma was revealed on histopathological examination. Breast MRI was performed to exclude multicentric carcinoma. In the inner quadrant of the right breast, hypointense on T1 sequences and heterogeneous hyperintense on T2 sequences, irregular mass formations was seen on MRI (Figure 3). Diffusion restriction was detected on diffusion-weighted images and heterogeneous enhancement was observed within lesions. Patient underwent mastectomy.

\section{Discussion}

The morphological features including margin of the lesion, orientation, shape, border and echogenicity are considered in differentiation of breast lesions on USG.

Citation: Altunkeser A, Arslan FZ (2019) Shear Wave Elastography as an Early Indicator of Breast Cancer in a Breastfeeding Patient: A Case Report and Literature Review. Clin Med Rev Case Rep 6:259. doi. org/10.23937/2378-3656/1410259

Accepted: March 23, 2019: Published: March 25, 2019

Copyright: (c) 2019 Altunkeser A, et al. This is an open-access article distributed under the terms of the Creative Commons Attribution License, which permits unrestricted use, distribution, and reproduction in any medium, provided the original author and source are credited. 


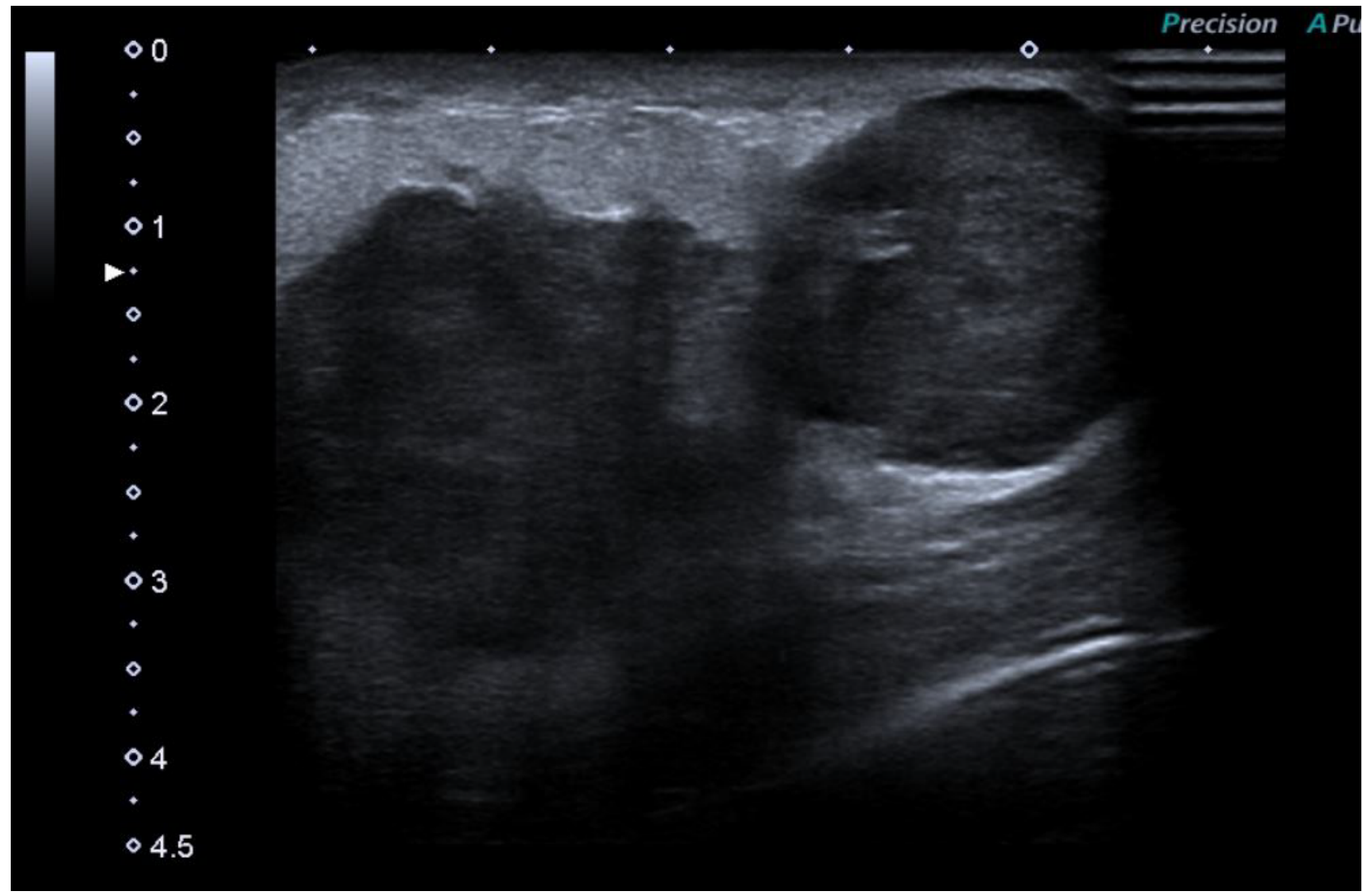

Figure 1: A hypoechoic mass lesions was sonographically detected on the right breast in a diameter with $31 \times 24 \mathrm{~mm}$.
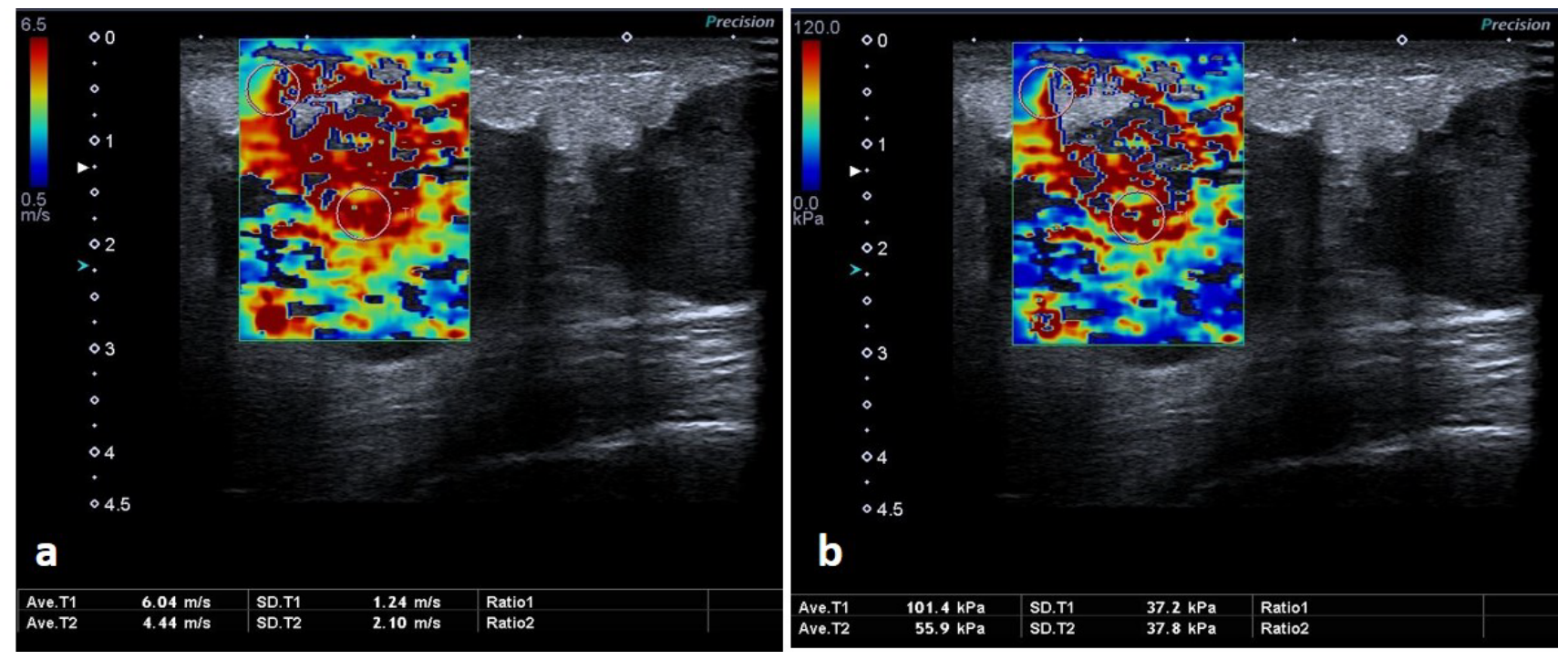

Figure 2: $a, b)$ On SWE images; Any stiff areas observed within mass lesion on color elasticity mapping. Mean elasticity value was $6.04 \mathrm{~m} / \mathrm{s} 101.4 \mathrm{kPa}$ on consecutive measurement.

It is a known fact that malignant lesions are usually palpated as a hard mass in the physical examination. Unfortunately, USG does not provide information about the stiffness of the lesion. A qualitative broad information can obtain about the tissue elasticity by integrating SWE into the classical USG evaluation. In our patient SWE examination prevented a possible delay in diagnosis in our young who has breastfeeding patient. It is a known fact that malignant mass lesions are harder with the palpation compared to benign lesions. Recently, many researchers reported that elasticity measurements can faciliated to establish correct diagnosis [3-5]. While Olgun, et al. [4] reported that even $37.1 \mathrm{kPa}$ as a mean elasticity cut-off values is a confident marker in differentiating malign lesion from benign [6-8], many researchers suggested that higher mean elasticity values varying between $65 \mathrm{kPa}$ to $80 \mathrm{kPa}$ is more reliable $[6,8,9]$. In our case report; we measured higher elasticity values in our malign lesion $101.4 \mathrm{kPa}$ on consecutive measurement, which was highy suggestive of malignancy. 

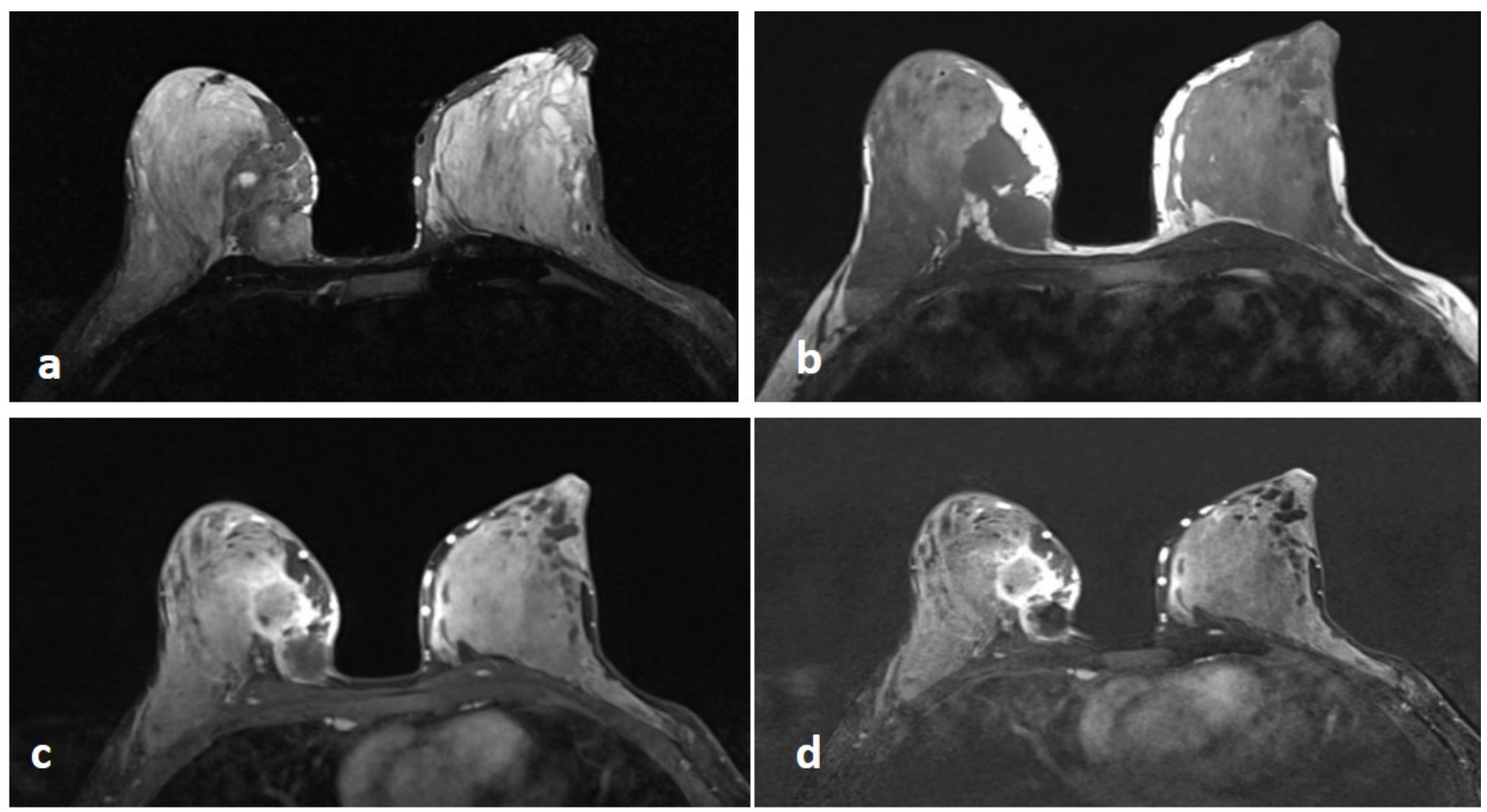

Figure 3: In the inner quadrant of the right breast, hypointense on axial T1 sequence (a) and heterogeneous hyperintense on axial T2 sequence (b), (c) early and late (d) enhanced axial sequences are demonstrated irregular mass formations was seen on MRI.

In conclusion; integration SWE measurement into USG examination may useful in differing malign lesions from benign ones.

\section{References}

1. Lee SH, Moon WK, Cho N, Chang JM, Han W, et al. (2014) Shear-wave elastographic features of breast cancers: Comparison with mechanical elasticity and histopathologic characteristics. Invest Radiol 49: 147-155.

2. Zhou JQ, Zhan WW, Chang C, Zhang XX, Jia Y, et al. (2014) Breast lesions: Evaluation with shear wave elastography, with special emphasis on the stiff rim sign. Radiology 272: 63-72.

3. Goddi A, Bonardi M, Alessi S (2012) Breast Elastography: A literature review. J Ultrasound 15: 192-198.

4. Olgun DC, Korkmazer B, Kilic F, Dikici AS, Velidedeoglu M, et al. (2014) Use of shear wave elastography to differentiate benign and malignant breast Lesions. Diagn Interv Radiol 20: 239-244.
5. Klotz T, Boussion V, Kwiatkowski F, Dieu-de Fraissinette V, Bailly-Glatre A, et al. (2014) Shearwave elastography contribution in ultrasound diagnosis management of breast lesions. Diagn Interv Imaging 95: 813-824.

6. Berg WA, Cosgrove DO, Doré CJ, Schäfer FK, Svensson WE, et al. (2012) Shear-wave elastography improves the specificity of breast US: The BE1 multinational study of 939 masses. Radiology 262: 435-449.

7. Kim MY, Cho N, Yi A, Koo HR, Yun BL, et al. (2013) Sonoelastography in distinguishing benign from malignant complex breast mass and making the decision to biopsy. Korean J Radiol 14: 559-567.

8. Chang JM, Won JK, Lee KB, Park IA, Yi A, et al. (2013) Comparison of shear-wave and strain ultrasound elastography in the differentiation of benign and malignant breast lesions. AJR Am J Roentgenol 201: 347-356.

9. Acharya UR, Ng WL, Rahmat K, Sudarshan VK, Koh JEW, et al. (2017) Shear wave elastography for characterization of breast lesions: Shearlet transform and local binary pattern histogram techniques. Comput Biol Med 91: 13-20. 